\title{
Reconstruction of gluteal defects related to Nicolau Syndrome secondary to intramuscular injection of diclofenac sodium with negative pressure wound therapy followed by skin graft
}

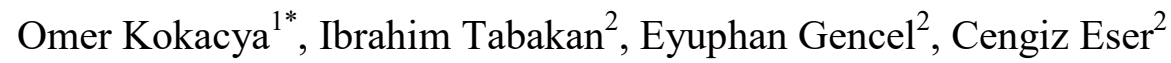

\begin{abstract}
Objective: Nicolau syndrome, synonymously livedo-like dermatitis or embolia cutis medicamentosa is a rare complication of drug injection leading to locoregional necrosis of the skin, adipose and muscular tissue. Underlying physiopathology is not well understood and there is no standart guideline for its management. However, after the demarcation of necrosis, debridement and for large wounds reconstruction is mandatory. Even though vast majority of the Nicolau syndrome cases were reported by other disciplines but the plastic surgery, there may be further need for reconstructive procedures for wound closure.

Material and Methods: Present study included eight patients admitted to our wound care center for necrosis at the gluteal region after intramuscular injection of diclofenac sodium who were treated with debridement, negative pressure wound therapy and skin grafts. Patients' ages, sexes, body mass indexes, underlying diseases were documented. Sizes of the lesions were measured. Injection, hospitalization, skin graft operation and discharge dates were recorded.

Results: All the wounds healed uneventfully but with depressed scars. Mean duration of hospitalization was 23.5 (range, 15-34) days.

Conclusion: In the present article, we reported that even if the hospitalization time is longer and cosmetic result is poorer, skin grafting after sufficient times of negative presure wound therapy administration is a reliable method. We do not recommend this method as the first choice but if there is not adequate adjacent soft tissue for harvesting flaps or if a suitable perforator vessel is not found for peforator flap harvest, this reliable method should be kept in mind.
\end{abstract}

Key Words: Nicolau syndrome; Diclofenac, Gluteal defect; Negative pressure wound therapy; Skin graft

\section{Introduction}

Nicolau syndrome, synonymously livedo-like dermatitis or embolia cutis medicamentosa is a rare complication of drug injection leading to locoregional necrosis of the skin, adipose and muscular tissue. It was first described by Freuhdenthal (1) in 1924 and Nicolau (2) in 1925 after intramuscular injection of bismuth salt for the treatment of syphilis.

Nicolau syndrome has been reported after injection of many other drugs such as non-steroidal antiinflammatory drugs $(3,4)$, benzathine penicillin (5), buprenorphine (6), bortezomib (7), hyaluronic acid (8), oxytocin (9), glatiramer acetate (10), glucocorticoid (11), vitamin K (12), pneumococcal conjugate vaccine (13) and other vaccines (14). It may be seen following intramuscular $(3-5,9,12)$, subcutaneous $(7,10,14)$ intraarticular (11), intraarterial, intravenous, failed extravascular injections (6), intradermal mesotherapy (15) and sclerotherapy (16) applications.

Even though vast majority of the Nicolau syndrome cases were reported by other disciplines but the plastic surgery, there may be further need for reconstructive procedures for wound closure.

In the present study, the authors reported eight cases of gluteal skin defects due to Nicolau syndrome secondary to intramuscular injection of diclofenac sodium, which were treated with surgical debridement, negative pressure wound therapy and skin grafts. Treatment methods are discussed. 


\section{Material and Methods}

The study included 8 patients admitted to our wound care center between April 2015 and April 2016 for necrosis at the gluteal region after intramuscular injection of diclofenac sodium who were treated with debridement, negative pressure wound therapy and skin grafts.

All patients were admitted to our clinic after demarcation of necrosis. If the demarcation of necrosis was not complete at the initial examination, the patients were followed up at outpatient clinic and they were hospitalized when the demarcations processes were complete.

For seven patients included in the study, sharp debridement was performed at the admission within the patient's bedside without need for local anesthesia and wound swab culture was obtained. In figure $1 \mathrm{~A}$ and $1 \mathrm{~B}$, patient no: 2 at the admission and just after sharp debridement, respectively are seen.

Then negative pressure wound therapy (Genadyne XLR8, Genadyne Biotechnologies, Great Neck, NY, USA) was administered and dressing was changed at 3 days intervals. When necessary, debridement was performed at every dressing change. One patient's (patient no:8) wound was debrided at another hospital and he was referred to our clinic for wound closure. After wound swab culture was obtained, negative pressure wound therapy was administered without need for debridement.

Wound swab cultures were repeated at every second dressing change. Patients with pathogen-positive culture results were given antibiotics chosen on the basis of the antibiogram results. Patients with pathogen-negative culture results were not given any antibiotics.

After leakage was stopped, necrotic tissues were removed and cavity was filled, split thickness skin grafts were used to cover the wounds. Operations were performed under spinal anesthesia. Patients were followed up at prone position with strict immobilization at postoperative 3 days.

Patients' ages, sexes, body mass indexes underlying diseases were documented. Sizes of the lesions were measured. Injection, hospitalization, skin graft operation and discharge dates were recorded

\section{Results}

Demographic and clinical characteristics of patients included in the study are presented in Table 1. Mean age was 63.5 (range, 48-75). Mean BMI was 34.5 (range 23-45). Mean wound size $(\mathrm{cm} 2)$ was 109 (range, 35-270).Time intervals between injection, hospitalization, skin graft operation and discharge are presented in Table 2 .
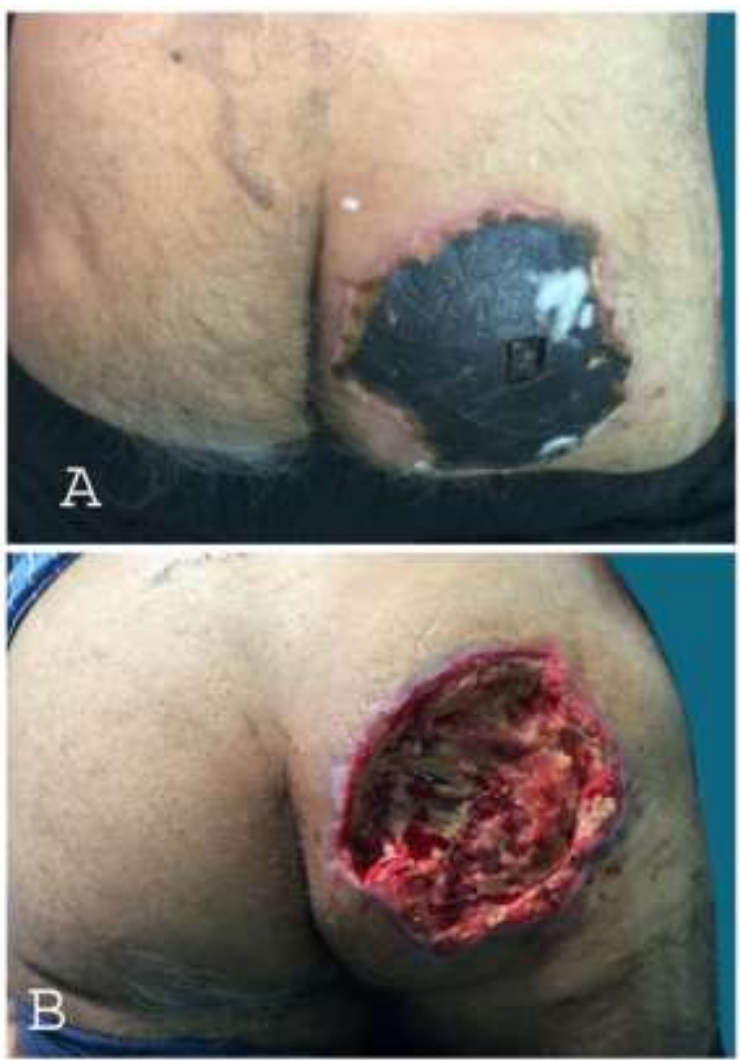

Figure 1: Patient no:2 A. at the admission B. just after sharp debridement

Mean time interval between injection and hospitalization was 16 (range, 7-35) days. Mean time interval between hospitalization and skin graft operation was 14 (range, 9-21) days. Mean time interval between skin graft operation and discharge was 9.4 (range, 6-13) days. Mean duration of hospitalization was 23.5 (range, 15-34) days

In Figure 2A patient no:8 at the admission is seen. Figure 2B shows the same patient after 14 days of negative pressure wound therapy and just before the skin graft operation. Figure $2 \mathrm{C}$ shows the same patient at postoperative 24 th day of skin grafting operation 
Table 1. Demographic and clinical characteristics of the patients

\begin{tabular}{|c|l|c|c|l|c|c|}
\hline $\begin{array}{c}\text { Patient } \\
\text { no }\end{array}$ & Sex & Age & BMI & Comorbidities & $\begin{array}{c}\text { Wound size } \\
(\mathrm{cm} \times \mathrm{cm})\end{array}$ & $\begin{array}{c}\text { Wound size } \\
\left(\mathrm{cm}^{2}\right)\end{array}$ \\
\hline 1 & Female & 72 & 34 & $\begin{array}{l}\text { Essential hypertension } \\
\text { Diabetes mellitus }\end{array}$ & 56 \\
\hline 2 & Male & 73 & 24 & Monoparesis & $14 \times 15$ & 210 \\
\hline 3 & Female & 62 & 38 & & $12 \times 9$ & 108 \\
\hline 4 & Female & 54 & 45 & Chronic osreoarthritis & 6 X11 & 66 \\
\hline 5 & Female & 58 & 42 & Diabetes mellitus & $6 \times 9$ & 54 \\
\hline 6 & Female & 48 & 37 & Diabetes mellitus & $5 \times 7$ & 70 \\
\hline 7 & Female & 75 & 33 & Essential hypertension & $18 \times 15$ & 270 \\
\hline 8 & Male & 66 & 23 & Primary lung cancer & & 35 \\
\hline
\end{tabular}

Table 2. Time intervals between injection, hospitalization, skin graft operation and discharge

\begin{tabular}{|c|c|c|c|c|}
\hline $\begin{array}{c}\text { Patient } \\
\text { no }\end{array}$ & $\begin{array}{c}\text { Time interval between } \\
\text { injection and } \\
\text { hospitalization (days) }\end{array}$ & $\begin{array}{c}\text { Time interval between } \\
\text { hospitalization and skin } \\
\text { graft operation (days) }\end{array}$ & $\begin{array}{c}\text { Time interval between } \\
\text { skin graft operation and } \\
\text { discharge (days) }\end{array}$ & Inpatient days \\
\hline 1 & 9 & 12 & 9 & 21 \\
\hline 2 & 23 & 21 & 12 & 33 \\
\hline 3 & 15 & 9 & 8 & 17 \\
\hline 4 & 13 & 21 & 7 & 19 \\
\hline 5 & 7 & 12 & 6 & 15 \\
\hline 6 & 16 & 9 & 9 & 24 \\
\hline 7 & 12 & 15 & 11 & 25 \\
\hline 8 & 35 & 14 & & 7 \\
\hline
\end{tabular}
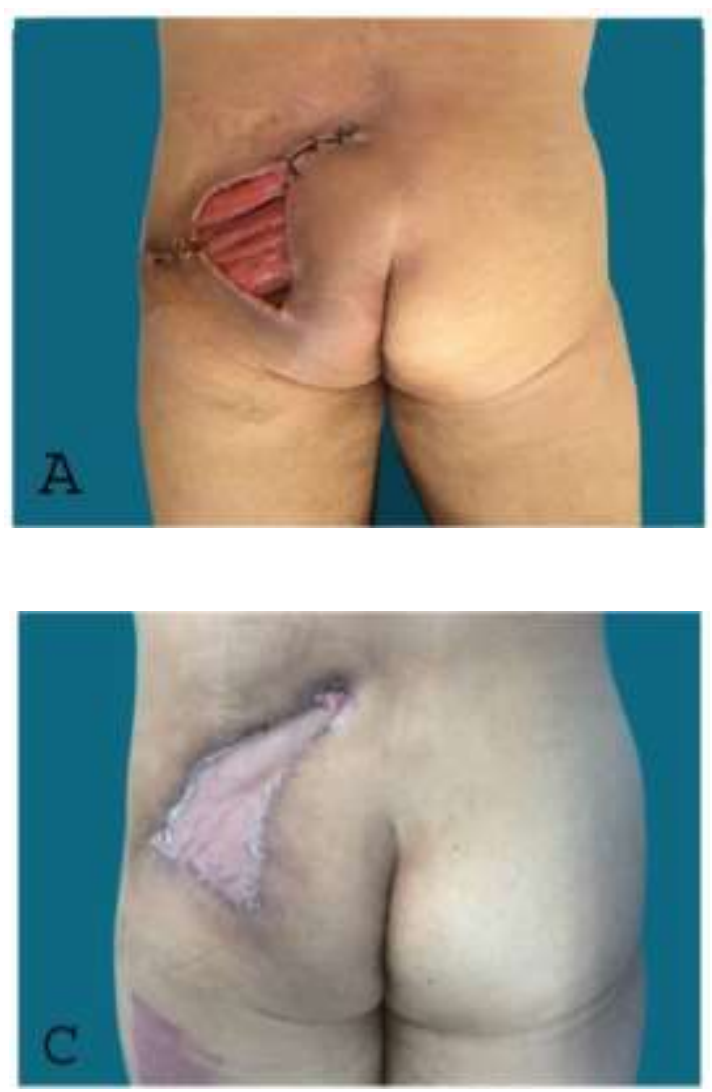

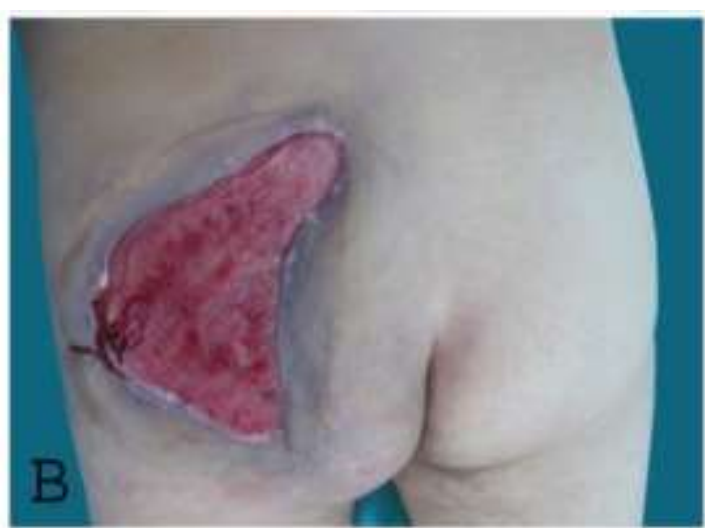

Figure 2: Patient no:8 A: at the admission B: after 14 days of negative pressure wound therapy and just before skin graft operation C: at the postoperative 24th day of skin graf operation 


\section{Discussion}

The actual physiopathology of Nicolau syndrome is not clear. It is presumed to be the result of direct damage, occlusion or indirect damage of an end-artery at the injection site. Most commonly hypothized two mechanisms are direct end-artery damage with injection needle and vasospasm as a result of periarterial injection. Other one is vascular rupture due to perivascular inflammation from a cytotoxic reaction to the drug. Embolic occlusion may be the result of inadvetently intra-arterially injected drug or perivascularly injected lipophilic drugs may penetrate the blood vessels and induce occlusion(4).

Non-steroidal anti-inflammatory drugs inhibit the enzyme cyclooxygenase, preventing thus the synthesis of prostaglandin, consequently inducing vasospasm and restriction of local circulation may contribute locoregional tissue necrosis(17). Diclofenac is one of the most commonly reported Nicolau syndrome causing drugs(18).

Regardless of the drug used and underlying physiopathology, once Nicolau syndrome developed, there is no spesific conservative treatment before the demarcation of necrotic area. In most cases pain control, antibiotics and dressings may help. Steroids, anticoagulants and vasoactive agents have been emphasized for regression of livedoid lesions but tissue damage has not been reversible(19).

Ergul et.al.'s case report of a pediatrics patient claims that hyperbaric oxygen therapy with vasoactive agents started within the 24 hours of the Nicolau syndrome diagnosis can prevent the development of necrosis and tissue loss(20).

After the demarcation of the necrotic area, necrotic tissue must be debrided and one must look for the ways of closing the wound. Small defects can be closed primarily and also can be left for secondary healing or treated with negative pressure wound closure systems. Best aesthetic results are obtained by primary closure. However, larger defects may not be closed by primary closure. For the reconstruction of larger defects graft or flap should be employed. In the study of Dadaci(3) et al with 17 patients, 4 of the defects were repaired with flaps following vacuum assisted wound therapy.

Mean hospitalization duration of these 4 patients is 11,8 (range, 10-12) and is shorter than our result. In the study by Kocman Et al. 5 patients were treated with immediate debridement and free style perforator based flaps. The time interval between debridement and wound closure operation is not seen in Kocman et al.'s study and this decreases the hospitalization time. There is no doubt that cosmetic results of flap reconstruction are superior than skin grafting as skin grafting results in depressed scars.
Before the definitive surgery, administering negative pressure wound therapy after drainage and debridement ensures the closure of pockets and contributes to healing by increasing wound granulation and blood flow(3). If there is not adequate adjacent soft tissue for harvesting flaps or if a suitable perforator vessel is not found for peforator flap harvest, closing the wound with skin grafting after sufficient times of negative pressure wound therapy administration is a reliable method.

\section{Conclusion}

Nicolau syndrome is the ischemic necrosis of skin, adipose and muscular tissue following drug injection. It can be seen after any type of injection of any kind of drugs. Underlying physiopathology is not well understood and there is no standart guideline for its management. However, after the demarcation of necrosis, debridement and for large wounds reconstruction is mandatory. In the present article, we reported that even if the hospitalization time is longer and cosmetic result is poorer, skin grafting after sufficient times of negative pressure wound therapy administration is a reliable method. We do not recommend this method as the first choice but if there is not adequate adjacent soft tissue for harvesting flaps or if a suitable perforator vessel is not found for perforator flap harvest, this reliable methos should be considered.

Conflict of Interest: The authors declare no potential conflicts of interest with respect to the research, authorship, and/or publication of this article.

Ethical issues: All authors declare that originality of research/article etc... and ethical approval of research, and responsibilities of research against local ethics commission are under the authors responsibilities. The study was completed due to defined rules by the Local Ethics Commission guidelines and audits.

Aknowledgement: All of the authors have made substantial contributions to the conception and design of this study, to the acquisition of data, or to the analysis and interpretation of data; similarly, all of the authors contributed to the drafting of the article or critical revision for important intellectual content.

\section{References}

1. Freudenthal W. Lokales embolisches bismogenolExanthem. Arch Dermatol Syph. 1924;147:155-60.

2. Nicolau S. Dermite livédoide et gangréneuse de la fesse, consécutive aux injections intra-musculaires, dans la syphilis. Ann mal vénér. 1925;20:321-9.

3. Dadaci M, Altuntas Z, Ince B, Bilgen F, Tufekci O, Poyraz N. Nicolau syndrome after intramuscular injection of nonsteroidal anti-inflammatory drugs (NSAID). Bosn J Basic Med Sci. 2015;15(1):57-60. 
4. Kim SK, Kim TH, Lee KC. Nicolau syndrome after intramuscular injection: 3 cases. Arch Plast Surg. 2012;39(3):249-52.

5. Noaparast M, Mirsharifi R, Elyasinia F, Parsaei R, Kondori $\mathrm{H}$, Farifteh S. Nicolau syndrome after intramuscular benzathine penicillin injection. Iran $\mathrm{J}$ Med Sci. 2014;39(6):577-9.

6. Wainstein L, Bernier C, Gerardin M, Bouquie R, Espitia O, Mussini JM, et al. Livedo-like dermatitis and necrotic lesions after high-dose buprenorphine injections: a national French survey. Br J Dermatol. 2015;172(5):1412-4.

7. Almudimeegh A, Le Pelletier F, Dupin N. Nicolau syndrome secondary to subcutaneous Bortezomib injection. J Eur Acad Dermatol Venereol. 2016;30(2):348-50.

8. Andre P, Haneke E. Nicolau syndrome due to hyaluronic acid injections. J Cosmet Laser Ther. 2016:1-19.

9. Seremet S, Turan E, Erdemir AT. Nicolau syndrome following intramuscular injection of oxytocin in pregnant women: report of two cases. Dermatol Online J. 2015;21(8).

10. Zecca C, Mainetti C, Blum R, Gobbi C. Recurrent Nicolau syndrome associated with subcutaneous glatiramer acetate injection--a case report. BMC Neurol. 2015;15:249.

11. McKinney C, Sharma N, Jerath RS. Livedoid dermatitis (Nicolau syndrome) following intra-articular glucocorticoid injection. J Clin Rheumatol. 2014;20(6):339-40.

12. Koklu E, Sarici SU, Altun D, Erdeve O. Nicolau syndrome induced by intramuscular vitamin $\mathrm{K}$ in a premature newborn. Eur J Pediatr. 2009;168(12):1541-2.
13. Alsuwaidi AR, Albawardi A, Khan NH, Souid AK. A 4month-old baby presenting with dermal necrotizing granulomatous giant cell reaction at the injection site of 13valent pneumococcal conjugate vaccine: a case report. J Med Case Rep. 2014;8:285.

14. Tierce MLt, Schultz SM, Lanier BQ. Tissue loss with subcutaneous immunotherapy-Nicolau syndrome. J Allergy Clin Immunol Pract. 2016;4(1):154-5.

15. Zaragoza J, Delaplace M, Benamara M, Esteve E. [A rare side effect of mesotherapy: Nicolau syndrome]. Ann Dermatol Venereol. 2013;140(11):713-7.

16. Korkomaz J, Maatouk I, Moutran R, Helou J. Images in vascular medicine. Nicolau livedoid dermatitis occurring after sclerotherapy. Vasc Med. 2014;19(5):415-6.

17. Ezzedine K, Vadoud-Seyedi J, Heenen M. Nicolau syndrome following diclofenac administration. British journal of dermatology. 2004;150(2):385-6.

18. Kocman EA, Yasar FN, Kose AA, Cil Y, Karabagli Y, Cetin C. Freestyle Perforator-Based Fasciocutaneous Flap Reconstruction in Nicolau Syndrome-Related Tissue Necrosis. Indian J Surg. 2015;77(Suppl 3):1187-90.

19. Corazza M, Capozzi O, Virgili A. Five cases of livedo-like dermatitis (Nicolau's syndrome) due to bismuth salts and various other non-steroidal anti-inflammatory drugs. Journal of the European Academy of Dermatology and Venereology. 2001;15(6):585-8.

20. Ergul Y, Soydemir D, Tastan Y, Omeroglu RE. Does early hyperbaric oxygen therapy prevent extremity necrosis in Nicolau syndrome? Pediatr Int. 2012;54(3):e15-8.

Copyright (C) 2016 The Author(s); This is an open-access article distributed under the terms of the Creative Commons Attribution License (http://creativecommons.org/licenses/by/4.0), which permits unrestricted use, distribution, and reproduction in any medium, provided the original work is properly cited. All Rights reserved by international journal of Medical Science and Discovery. 